\title{
Self-burial of objects on sandy beds by scour: A synthesis of observations
}

\author{
C.T. Friedrichs \\ Virginia Institute of Marine Science, College of William \& Mary, Gloucester Point, Virginia, USA \\ S.E. Rennie \& A. Brandt \\ Johns Hopkins University Applied Physics Laboratory, Laurel, Maryland, USA
}

\begin{abstract}
Factors that influence equilibrium, scour-induced burial depth $(B)$ in sand relative to object diameter $(D)$ are examined through analysis of over 750 observations. The main factors that increase scourinduced $B / D$ under steady currents without waves are found to be an increased Shields parameter $(\theta)$ and small $D(<3 \mathrm{~cm})$, with separate power laws applicable to clear-water and live-bed conditions. For larger $D$, greater cylinder density also increases $B / D$ under steady currents. The main factor that increases scourinduced $B / D$ under wave-dominated conditions is an increased Keulegan-Carpenter number. $B / D$ additionally increases as the mean current component parallel to wave orbitals decreases. For cylinders under waves, $B / D$ also increases as $\theta$ increases and as the angle between wave orbitals and a cylinder's axis increases. All else being equal, tapered cylinders bury most, followed by cylinders, then spheres, and conical frustums bury least. Parameterized models dependent on the above variables explain $85 \%$ of observed variance in $B / D$.
\end{abstract}

\section{INTRODUCTION}

When an object sitting on the bed extends above the surrounding bed roughness, the object will alter the local flow pattern relative to the far field boundary layer. Such perturbations increase the velocities and stresses impinging on surface sediment immediately adjacent to the object. Nearby grains tend to be dispersed, resulting in a scour pit or pits that deepen until the tendency for sediment to be dispersed is balanced by a tendency for sediment to fall back into the pit(s). The difference in pressure at the bed upstream and downstream of the object may also drive seepage flow that can cause piping and tunnel erosion under the object (Whitehouse 1998, Sumer and Fredsøe, 2002, Voropayev et al., 2003).

As a result of the above processes, the object may eventually become unstable and settle into the scoured depression, reducing the object's exposure height (Fig 1). For a given object, surrounding sediment, and far field hydrodynamics, an equilibrium value for the depth of scour-induced self-burial $(B)$ is anticipated to be a function of the far field waves and currents, the properties of the surrounding sediment, and the size, shape and density of the object (Sumer and Fredsøe, 2002, Cataño-Lopera et al., 2007, 2011).

This paper, which was motivated by possible threats to safety associated with the presence of abandoned, unexploded underwater munitions (SERDP, 2009), presents a compilation and analysis of existing data on equilibrium self-burial depth for objects on sandy beds as induced by local scour. More than 750 observations of equilibrium depths of self-burial depth $(B)$ for objects subject to scour on sandy beds were identified from the literature. Cylinders were the most commonly studied object type (> 500 cases), with existing data spanning diameters $(D)$ from 1 to $50 \mathrm{~cm}$, length-to-diameter ratios $(L / D)$ from 2 to 30, and object densities relative to water $\left(\rho_{o} / \rho\right)$ from 1 to 10 . Median sand diameter $\left(d_{50}\right)$ ranged from 0.1 to $0.7 \mathrm{~mm}$, maximum near-bed wave plus current velocity $\left(U_{\mathrm{m}}\right)$ ranged from 0.1 to $1.3 \mathrm{~m} / \mathrm{s}$, and cases including waves had wave periods $(T)$ ranging from 1 to $12 \mathrm{~s}$. Other object types for which $B$ was documented in the literature include spheres, tapered cylinders, and conical frustums.

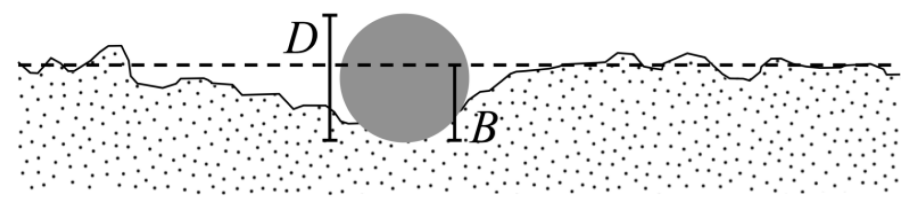

Figure 1. Schematic of an object of diameter, $D$, that has buried to an equilibrium depth, $B$, below the mean height of the far field sand bed. Modified from Cataño-Lopera et al. (2007).

\subsection{Primary controls on equilibrium burial depth}

Two parameters have been identified most often in the literature as fundamental, overarching controls on the equilibrium depth of self-burial by scour for 
objects on sandy beds: the Shields parameter and the Keulegan-Carpenter number.

The Shields parameter $(\theta)$, which is a dimensionless representation of bed shear stress $\left(\tau_{b}\right)$, is given by:

$$
\theta=\frac{\tau_{b}}{\left(\rho_{s}-\rho\right) g d_{50}}
$$

where $\rho_{\mathrm{S}}$ is grain density $\left(2.65 \mathrm{~g} / \mathrm{cm}^{3}\right.$ for quartz sand), $\rho$ is fluid density (taken here to be $1.0 \mathrm{~g} / \mathrm{cm}^{3}$ ), $g$ is acceleration due to gravity $\left(9.81 \mathrm{~m}^{2} / \mathrm{s}\right)$, and $d_{50}$ is the median sand grain size. The Shields parameter is proportional to the drag force acting on a sand grain, which tends to mobilize the grain, divided by the immersed weight of the sand grain, which tends to keep the grain stationary.

If an object enhances turbulence enough to initiate local sediment motion, but far-field $\theta$ is below its critical value for sediment motion $\left(\theta_{c r}\right)$, then scour around the object is known as clear-water scour. For $\theta>\theta_{c r}$, (where $\theta_{c r} \approx 0.03$ to 0.06 for well-sorted sand with $\left.\left(\tau_{b} / \rho\right)^{1 / 2} d_{50} / v^{3} \square \square\right)$, scour around an object is known as live-bed scour (Whitehouse, 1998). by:

The Keulegan-Carpenter number $(K C)$, is given

$K C=U_{m} T / D$

where $U_{m}$ is maximum near-bed wave plus current velocity, $T$ is wave period, and $D$ is object diameter. $K C$ is proportional to the ratio of the maximum orbital particle excursion distance, $A=U_{m} T /(2 \pi)$, to the object diameter, such that $K C=2 \pi A / D$. (Note that $U_{m} \geq U_{w}$, where $U_{w}$ is the amplitude of the wave orbital velocity alone; i.e., $U_{m}$ includes the near-bed mean current, $U_{c}$, while $U_{w}$ does not.)

If $K C$ is small, vortices are more likely to be concentrated closer to the object, while if $K C$ is large, vortices will be swept farther from the object. Thus narrower, steeper scour pits may be expected at small $K C$, while wider, more gently sloped scour pits may be expected at larger $K C$. Wider scour pits may then, in turn, shelter an object from ambient flow less, exposing the object to higher near-bed velocities and ultimately lead to deeper scour (Sumer and Fredsøe, 2002). $K C$ is also proportional to the ratio of the wave boundary thickness $(\delta)$ to object diameter, and it has previously been found that the depth of scour tends to increase with greater $\delta$. (Sumer and Fredsøe, 2002).

Based on the existing literature, it is not immediately clear if $\theta$ or $K C$ is typically more important, or if both are usually needed to successfully predict $B / D$. For individual sets of observed data describing the self-burial of objects by scour on sandy beds, several authors have previously found $\theta$ to be the dominant parameter (Whitehouse, 1998; CatañoLopera et al., 2007, Demir and García, 2007, Friedrichs 2007). Some have found only $K C$ to be necessary (Sumer et al., 2001; Truelsen et al., 2005; Cataño-Lopera et al., 2011); and others have argued that both are needed (Stansby and Starr, 1992; Voropayev et al., 2003; Cataño-Lopera and García, 2006.)

Table 1. Properties of cylinders and pipe segments used in self-burial by scour experiments. $N=$ reference number, $D=$ diameter (vertical dimension), $L=$ length (horizontal dimension), $\rho_{\mathrm{o}}=$ object density. Dashes indicate range of values reported.

\begin{tabular}{lllll}
\hline$N$ & \multicolumn{1}{c}{ Reference } & $\begin{array}{c}D \\
\mathrm{~cm}\end{array}$ & $\begin{array}{c}L \\
\mathrm{~cm}\end{array}$ & $\begin{array}{l}\rho_{\mathrm{o}} \\
\mathrm{g} / \mathrm{cm}^{3}\end{array}$ \\
\hline 1 Carstens \& Martin (1963) & $1.3-8.8$ & $5.1-35.1$ & 2.7 \\
2 & Starr (1989)* & $1.3-2.5$ & $15.0-45.0$ & $1.8-10.6$ \\
3 & Sumer \& Fredsøe (1994)* & 11.0 & 198 & $1.3-6$ \\
4 Sumer et al. (2001)* & $2.0-10.0$ & $59.4-198$ & $1.3-6$ \\
5 Cataño-Lopera (2005) & $5.1-25.4$ & $20.3-102$ & $2.0-7.8$ \\
6 Demir \& García (2007) & $7.5-12.5$ & $20.0-34.4$ & $2.3-7.8$ \\
7 Cataño-Lopera et al. (2007) & $8.6-10.0$ & $20.0-34.4$ & $2.3-2.7$ \\
8-14 ONR-MBP & $47.0-53.3$ & $150-203$ & $2.0-2.4$ \\
15 Rennie et al. (2016) & $2.5-10.5$ & $9.9-32.0$ & $1.2-7.9$ \\
\hline
\end{tabular}

*Cylinders horizontally fixed; others free to move horizontally. ${ }^{+}$Office of Naval Research Mine Burial Program data sources are Bower et al. (2007), Bradley et al. (2007), Friedrichs (2007), Mayer et al. (2007), Traykovski et al. (2007), Trembanis et al. (2007), Wolfson (2005), and Wolfson et al. (2007).

Table 2. Properties of additional shapes used in selfburial by scour experiments. Symbols as in Table 1 .

\begin{tabular}{|c|c|c|c|c|}
\hline$N$ & $\begin{array}{l}\text { Reference } \\
\text { (object shape) }\end{array}$ & $\begin{array}{c}D \\
\mathrm{~cm}\end{array}$ & $\begin{array}{c}L \\
\mathrm{~cm}\end{array}$ & $\begin{array}{c}\rho_{\mathrm{o}} \\
\mathrm{g} / \mathrm{cm}^{3}\end{array}$ \\
\hline & $\begin{array}{l}\text { Truelsen et al. (2005) } \\
\text { (spheres) }\end{array}$ & $3.0-7.3$ & $3.0-7.3$ & $2.0-4.0$ \\
\hline & $\begin{array}{l}\text { Cataño-Lopera et al. (2011) } \\
\text { (conical frustums) }\end{array}$ & $7.5-25.0$ & $15.0-50.0$ & 2.0 \\
\hline 18 & Pang \& Liu (2014) & 5.0 & 22.0 & 2.7 \\
\hline & $\begin{array}{l}\text { Rennie et al. (2016) } \\
\text { (tapered cylinders) }\end{array}$ & 7.9 & 31.8 & 2.4 \\
\hline
\end{tabular}

Table 3. Environmental properties associated with observations of equilibrium burial depth, including range of values. $N=$ reference number, $d_{50}=$ median sand size, $U_{w}=$ wave orbital velocity amplitude, $T=$ wave period, $U_{c}=$ current velocity, $h=$ water depth, $B / D=$ burial depth/object diameter.

\begin{tabular}{|c|c|c|c|c|c|c|}
\hline$N$ & $\begin{array}{l}d_{50} \\
\mathrm{~mm}\end{array}$ & $\begin{array}{c}U_{w} \\
\mathrm{~cm} / \mathrm{s}\end{array}$ & $\begin{array}{c}T \\
\mathrm{sec}\end{array}$ & $\begin{array}{l}U_{c} \\
\mathrm{~cm} / \mathrm{s}\end{array}$ & ec $h$ & $B / D$ \\
\hline $1 *$ & $0.30-0.59$ & $27-76$ & 3.6 & 0 & 0.15 & $0.29-1.59$ \\
\hline 2 & 0.22 & $0-29$ & $1.6-2.6$ & $0-37$ & 0.25 & $0.04-0.81$ \\
\hline $3-4$ & $0.18-0.20$ & $0-50$ & $1.5-3.5$ & $0-54$ & $0.20-0.33$ & $0.19-0.82$ \\
\hline 5 & 0.25 & $15-55$ & $1.4-6.9$ & $0-17$ & 0.56 & $0.02-0.77$ \\
\hline $6-7 *$ & 0.25 & $0-80$ & $3.0-12.0$ & $0-45$ & 0.60 & $0.15-1.00$ \\
\hline $8-14^{+}$ & $0.14-0.65$ & $50-128$ & $6.1-9.6$ & $10-40$ & 12 & $0.02-1.17$ \\
\hline 15 & 0.42 & 0 & $\infty$ & $20-60$ & 0.46 & $0.02-2.27$ \\
\hline 16 & 0.19 & $0-42$ & $1.1-480$ & $0-40$ & $0.30-0.54$ & $0.02-0.57$ \\
\hline 17 & 0.25 & $20-65$ & $1.5-5.7$ & $0-15$ & 0.60 & $0.02-0.15$ \\
\hline 18 & $0.12-0.21$ & $25-39$ & $1.5-2.0$ & 0 & 0.30 & $0.58-1.06$ \\
\hline 19 & 0.42 & 0 & $\infty$ & $30-58$ & 0.46 & $0.12-1.17$ \\
\hline
\end{tabular}

*U-tube; ${ }^{+}$field observations $\left(U_{w}=U_{w 10}\right)$; others lab flumes. 


\subsection{Additional controls on equilibrium burial depth}

When the direction of a relatively weak mean current is parallel to wave orbital velocity, the depth of scour under pipelines and self-burial of cylinders has been found to decrease as the strength of the nearbed mean current $\left(U_{c}\right)$ increases (up to $U_{c} / U_{m} \approx 0.5$ ) (Sumer and Fredsøe, 2002, Cataño-Lopera and García, 2006). This occurs because, if $U_{c}$ and $U_{w}$ are parallel, the wave and current oppose each other during half of wave cycle, reducing the intensity of the lee wake on one side.

Depth of scour under pipelines and self-burial of cylinders has also been found to decrease if the angle $(\alpha)$ between maximum velocity and a pipeline or cylinder's axis remains small throughout the scour process (Sumer and Fredsøe, 2002, Cataño-Lopera and García, 2007).

The density of the object $\left(\rho_{o}\right)$ can further affect $B / D$. Under conditions of a liquefied sand bed, pipelines tend to rise through the bed for $\rho_{o}<\rho_{c r}$, and sink for $\rho_{o}>\rho_{c r}$, where $\rho_{c r}$ is the critical density for object flotation (Sumer, 2014). In the absence of liquefaction, Cataño-Lopera and García (2006) still observed a tendency for heavy cylinders to bury deeper. Cataño-Lopera et al. (2007) found bed fluidization rather than classic scour to dominate burial of cylinders in sand for $\theta>\sim 0.7$ to 0.8 .

Far-field geological affects, including bedform migration (Voropayev et al., 1999), subsurface resistant layers (McNinch et al., 2006), and large-scale erosion or deposition (Jenkins et al., 2007), can also affect the burial depth of objects subject to scour on a sandy bottom. Since bedform height and length both scale with grain size, and objects settle at least to the base of troughs if bedform wavelengths are large compared to $D$ (Voropayev et al., 1999), one may expect $B / D$ to increase as $d_{50} / D$ increases (after accounting for the inverse effect of $d_{50}$ in $\theta$ ).

Finally, the shape of the object is likely to affect the depth of scour-induced burial. For example, Cataño-Lopero et al. (2011) found that conical frustums produce significantly less scour and self-burial than cylinders of similar $D$ under similar wave forcing. This is likely because cone shapes offer less resistance to flow than cylinders and thus shed weaker vortices (Sumer and Fredsøe, 2002).

\section{COMPILATION AND ANALYSIS METHODS}

Sufficiently complete data on the equilibrium selfburial depth of objects on sandy beds, associated object and sand properties, and wave and current forcing were identified in 18 papers, reports, theses and dissertations (Table 1 and Table 2). A total of 761 data points for $B / D$ were compiled, including 667 measurements for self-buried cylinders, 58 for conical frustums, 25 for spheres, and 11 for tapered cyl- inders. The data include 379 cases measured under waves only, 256 under waves plus mean currents, and 126 under steady currents; 694 are laboratory measurements, while 67 are field measurements. The complete compiled data sets are provided in digitized form in Friedrichs et al. (2016).

\subsection{Self-burial under mean currents only}

The far-field bed stress $\left(\tau_{b} / \rho=u_{*}{ }^{2}\right)$ under mean currents in the absence of waves was calculated following Yalin (1992) as presented in García (2008). The mean current, $U_{o b s}$, observed at height $z_{o b s}$ above the far-field mean bed elevation was used to solve for shear velocity, $u_{*}$, in

$$
\frac{U_{o b s}}{u_{*}}=\frac{1}{\kappa} \log \left(\frac{z_{o b s}}{k_{b}}\right)+B_{s}
$$

where $B_{s}$ in an empirical function of the roughness Reynolds number, $R e_{*}=u_{*} k_{b} / \mathrm{v}$, which is given by

$$
B_{s}=8.5+\left[2.5 \log \left(R e_{*}\right)-3\right] e^{-0.12\left[\log \left(R e_{*}\right)\right]^{2.42}}
$$

In the above, $v$ is kinematic viscosity of water (set to $\left.10^{-6} \mathrm{~m}^{2} / \mathrm{s}\right), \kappa=0.41$ is the von Karman constant, and $k_{b}=2.5 d_{50}$ is the bed roughness height. An advantage of Eqs. (3) - (4) is that they simultaneously represent hydraulically smooth and rough turbulence, as well as the transitional range between them (García, 2008).

The Shields parameter under mean currents was calculated via Eq. (1) using the value of $\tau_{b} / \rho=u_{*}{ }^{2}$ determined from Eqs. (3) - (4). In applying Eqs. (3) - (4) in our analysis, $u_{*}$ represents skin friction, and we do not adjust $u_{*}$ to compensate for the possible effects of bedforms. Under steady currents in the absence of waves, the value assigned to the KeuleganCarpenter number is $K C=\infty$.

\subsection{Self-burial under waves only}

Bed stress under waves in the absence of currents was calculated via the equation

$$
\tau_{b}=0.5 \rho f_{w} U_{w}^{2}
$$

where $f_{w}$ is the wave friction factor, and $U_{w}$ is the amplitude of the near-bed wave orbital velocity. All the wave-only data identified for this analysis was collected in lab flumes, and $U_{w}$ is taken to be equal to the amplitude of the near-bed orbital velocity as reported in the references or as calculated from observed wave height assuming linear wave theory. No further adjustment of $U_{w}$ was made to account for the elevation of the observation relative to the bed.

The wave friction factor was calculated using the formulation of Myrhaug and Slaattelid (1990) as presented by Demir and García (2007): 


$$
\begin{aligned}
& \frac{0.32}{f_{w}}-1.64=\left\{\log \left(6.36 f_{w}^{0.5} A / k_{b}\right)\right. \\
& \left.-\log \left[1-\exp \left(-0.262 \frac{R_{w} f_{w}^{0.5}}{\left(A / k_{b}\right)}\right)+\frac{4.71\left(A / k_{b}\right)}{R_{w} f_{w}^{0.5}}\right]\right\}^{2}
\end{aligned}
$$

where $R_{w}=U_{w} A / v$ is the wave Reynolds number and $A=U_{w} T /(2 \pi)$ is the amplitude of the wave orbital excursion distance. Like Eq. (4), Eq. (6) has the advantage of representing hydraulically smooth and rough turbulence as well as the transitional range between them (Demir and García, 2007). In the absence of currents, $K C=U_{m} T / D=U_{w} T / D$, because $U_{m}=U_{w}$ when $U_{c}=0$.

\subsection{Self-burial under waves plus mean currents}

For the case of waves plus mean currents, where $U_{c}$ is significantly less than $U_{w}$, Eqs. (5) and (6) can still be used to estimate $\tau_{b}$, but with $U_{w}$ supplemented by an appropriate contribution from $U_{c}$ (Cataño et al., 2011). The maximum wave plus current velocity $\left(U_{m}\right)$, which replaces $U_{w}$ in the presence of waves plus currents, was calculated in the present study as

$$
U_{m}=\sqrt{U_{w}^{2}+U_{c}^{2}+2 U_{w} U_{c} \mid \cos \beta}
$$

where $\beta$ is the angle between $U_{w}$ and $U_{c}$, and $U_{c}$ is calculated as described in Section 2.1. Under waves plus currents, $U_{m}$ is used in calculating $A, R_{w}$ and $f_{w}$, as well as $\tau_{b}$ and $K C$. For collinear combined waves and currents in wave flume observations, $\beta=0$.

For the field observations examined in this paper, $U_{w}$ in Eq. (7) was estimated from observations following the guidance of Myrhaug and Ong (2009) for a natural oceanic random wave spectrum. The orbital velocity amplitude corresponding to the highest $10 \%$ among random waves $\left(U_{w 10}\right)$ in a stationary narrow-band sea state is used here, as it is reasonable to assume that it is mainly the highest waves that are responsible for the scour process (Myrhaug and Ong, 2009). Here $U_{w}=U_{w 10}$ is calculated as $U_{w 10}=$ $2 \sigma_{\mathrm{U}}$ (Dean and Dalrymple, 1991), where $\sigma_{\mathrm{U}}$ is the standard deviation of the instantaneous velocity time-series over the course a $\sim 10$ minute "burst". Following Friedrichs (2007) and Friedrichs et al. (2016), the most energetic burst preceding each observation of $B / D$ is chosen to represent $U_{w}$. It is assumed that each high-energy wave event (each typically a day to several days in duration) lasted long enough for self-burial to reach its equilibrium value.

The field observations considered here were collected on the inner shelf, between 1 and $10 \mathrm{~km}$ offshore, and all at $h \approx 12 \mathrm{~m}$ (Trembanis et al., 2007). During wave events large enough to induce significant seabed scour at these locations, $U_{w}$ and $U_{c}$ tend to be at a relatively large angle to each other, and here we let $\beta=90^{\circ}$ in Eq. (7) for the field cases.

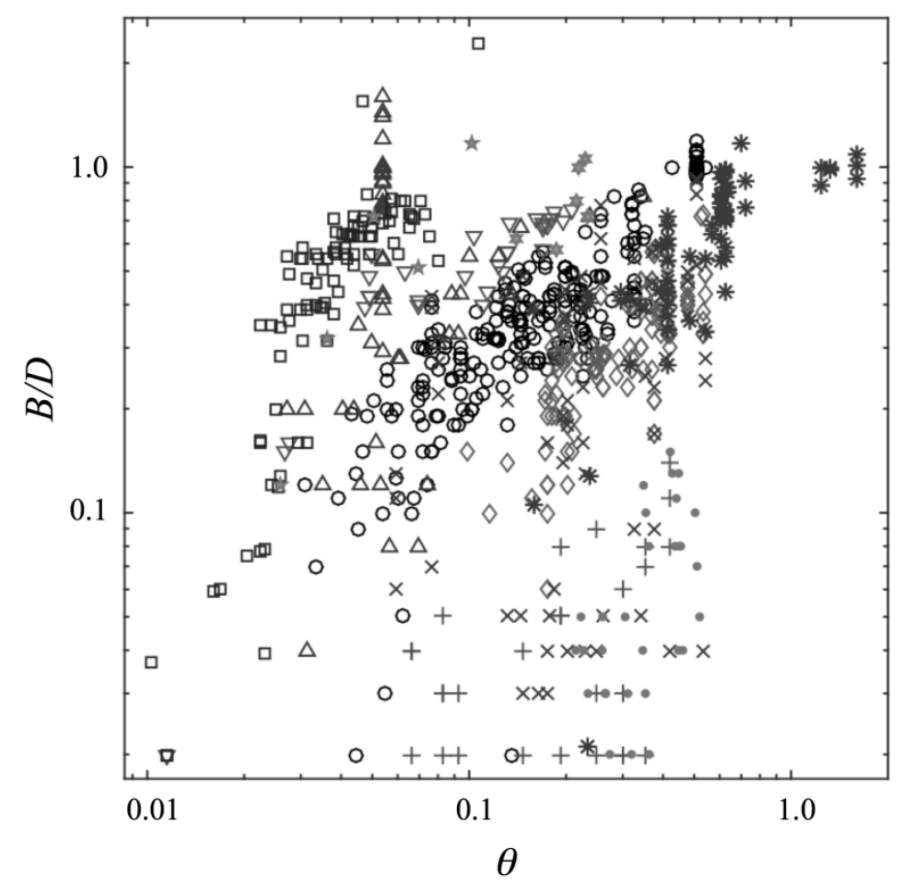

Figure 2. All observations of $B / D$ plotted as a function of $\theta$. Cylinders with waves plus currents in the field $=*$ (all others are lab measurements); cylinders with $\alpha<60^{\circ}=\times$ (all others have $\alpha \geq 60^{\circ}$ ); cylinders with $D<2.6 \mathrm{~cm}$ for waves only $=\Delta$ and for currents only $=\square$ (all other objects have $D \geq 3.0 \mathrm{~cm}$ ); other cylinders and spheres with currents only $=\nabla$; cylinders with waves plus currents $=\diamond$; cylinders and spheres with waves only $=0$; conical frustums with waves only $=+$; conical frustums with waves plus currents $=\bullet$; tapered cylinders with waves only $=\star$; tapered cylinders with currents only $=\star$

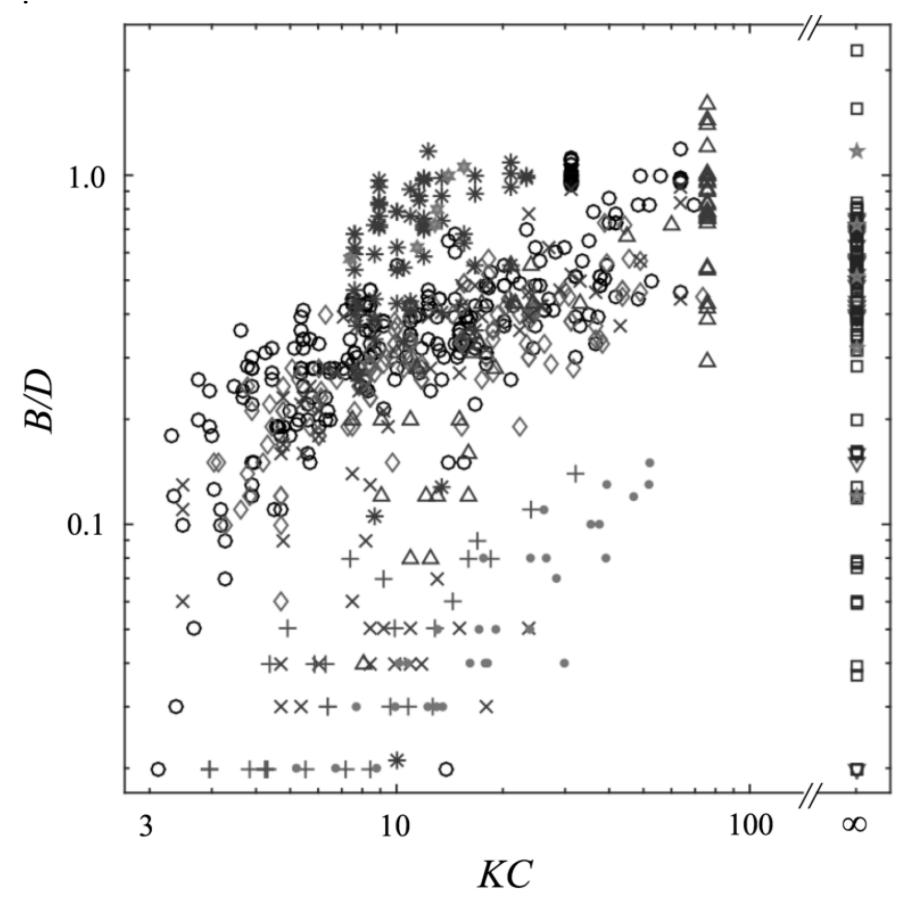

Figure 3. All observations of $B / D$ plotted as a function of $K C$. Symbols are as in Fig. 2.

Finally, Eqs. (3) - (4) were used to adjust $U_{o b s}$ to a consistent mean current reference value, $U_{c}$, that could be used to compare current forcing across experiments. Here we define $U_{c}$ to be the current speed that is predicted by Eqs. (3) - (4) at $z=D$. 


\section{RESULTS AND DISCUSSION}

The distinct trends in equilibrium burial depth seen for different classes of objects under various forcing scenarios in Fig. 2 and Fig. 3 strongly suggest that neither the Shields parameter $(\theta)$ alone nor the Keulegan-Carpenter number $(K C)$ alone can adequately predict equilibrium burial depth $(B / D)$ for all the available observations involving currents, waves, and combinations of both. For example, cylinders subject to currents alone systematically bury deeper at a given value of $\theta$ than similar objects subject to wave forcing (Fig. 2). And the cylinders observed in the field buried significantly deeper for a given value of $K C$ than cylinders observed in the lab (Fig. 3).

These and other distinct trends in $B / D$ as a function of $\theta, K C$, and additional parameters can be better understood by considering current- versus waveforced cases separately, and by systematically examining the influence of several of the possible governing factors for each case via an informal step-wise multiple regression.

\subsection{Self-burial by scour under mean currents only}

Although $K C=U_{m} T / D$ is correlated to $B / D$ under waves (Fig. 3), $K C$ cannot be used to predict different degrees of burial under mean currents because $K C$ is effectively infinite for all mean flows. Authors such as Sumer and Fredsøe (2002) who predict $B / D$ under mean flows based on $K C$ alone have argued that under conditions of live-bed scour $\left(\theta>\theta_{c r}\right)$, self-burying objects of the same shape will all eventually reach the same equilibrium burial depth (in the absence of bed liquefaction or other complicating effects as outlined in Section 1.2). For cylinders, Sumer et al. (2001) found the universal live-bed value of $B / D$ under mean currents to be about 0.7 , while for spheres, Truelsen et al. (2005) found the live-bed value of $B / D$ to be about 0.5 . These authors recognize that $\theta$ will still increase $B / D$ under clear-water scour, and $\theta$ also decreases the time-scale needed to reach equilibrium $B / D$ under live-bed conditions.

In contrast to $K C$, the Shields parameter, $\theta=$ $\tau_{b} /\left[\left(\rho_{\mathrm{s}}-\rho\right) g d_{50}\right]$, can effectively distinguish among mean current forcing scenarios as bottom stress and sand grain vary (Fig. 4). The data compiled for mean current forcing in Fig. 4 suggest that $B / D$ increases as a function $\theta$ for live-bed scour, as well as for clear-water scour, although the exponents relating $B / D$ to $\theta$ are of smaller magnitude for live-bed scour.

Relationships for clear-water and live-bed scour displayed in Fig. 4 were found by fitting relationships of the form $B / D=f_{\theta}=a \theta^{b}$ for $\theta$ greater and less than 0.04 , respectively. The intersection of the best-fit lines for clear-water and live-bed scour occurred near $\theta_{c r}=0.04$ for both smaller $(D<2.6 \mathrm{~cm})$ and larger $(D \geq 8.6 \mathrm{~cm})$ cylinders. (No burial data were identified in the literature for cylinders with $D$ between 2.6 and $8.6 \mathrm{~cm}$ under steady flow conditions.)

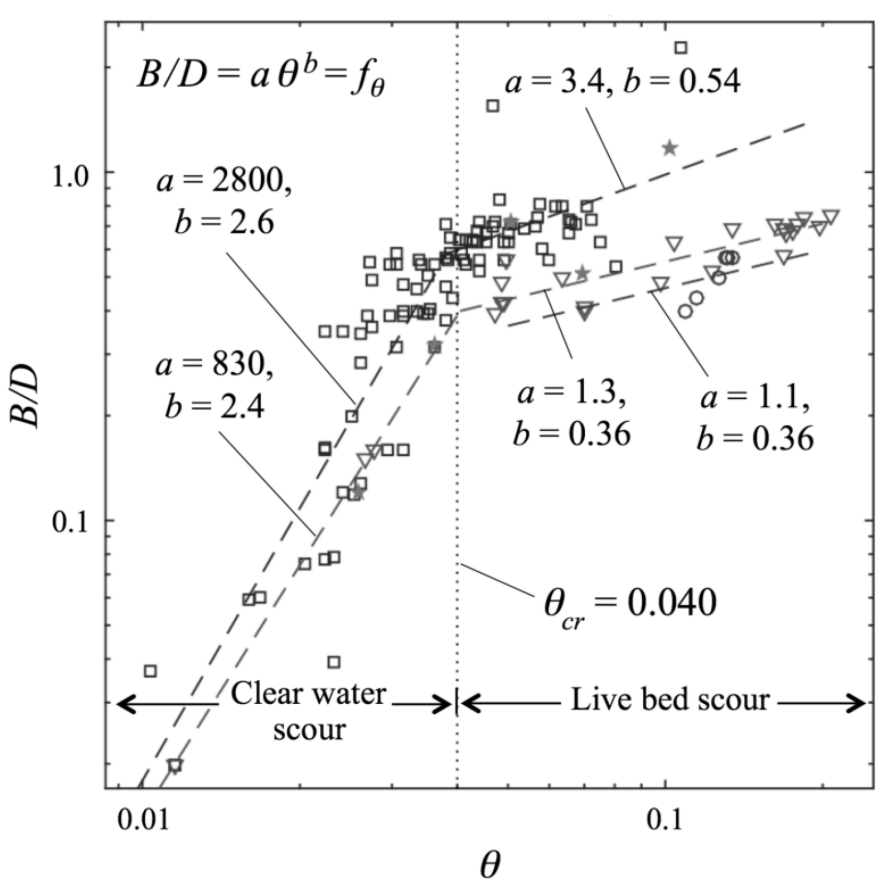

Figure 4. All observations of $B / D$ under steady currents in the absence of waves plotted as a function of $\theta$. Cylinders with $D$ $<2.6 \mathrm{~cm}=\square$; other cylinders (all $D \geq 8.6 \mathrm{~cm})=\nabla$; tapered cylinders $(D=8 \mathrm{~cm})=\star$; spheres $($ all $D \geq 3.0 \mathrm{~cm})=0$. The coefficients $a$ and $b$ displayed above and associated with the dashed lines are utilized in $f_{\theta}$ as part of the relations applied in Fig. 5 and Fig. 6. For $\theta<0.04$, the power-law fit to $\nabla$ is used for $\star$; for $\theta>0.04$, the power-law fit to $\square$ is used for $\star$.

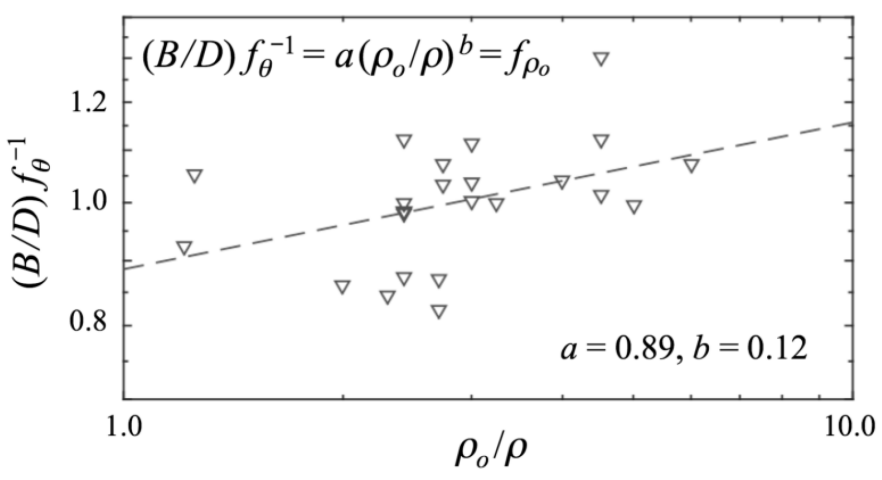

Figure $5 . B / D$ for steady currents normalized by the power-law relations from Fig. 4 and plotted as a function of $\rho_{\mathrm{O}} / \rho$ for large cylinders. Coefficients $a$ and $b$ in the above figure are associated with the dashed line and are utilized in $f \rho_{\mathrm{o}}$ as part of the relationship applied in Fig. 6. The above coefficient for $f \rho_{\mathrm{o}}$ is used only for large cylinders, $\nabla . f \rho_{\mathrm{o}}=1$ for the other object classes subject to steady currents in the absence of waves.

The dashed lines in Fig. 4 highlight different relationships between $\theta$ and $B / D$ for larger and smaller cylinders, especially under conditions of live-bed scour, with a distinct behavior seen in the available observations with $D<2.6 \mathrm{~cm}$. Small cylinders may bury deeper (in terms of $B / D$ ) because small cylinders are more likely to interact with sandy bedforms. A continuous relationship between $B / D$ and $d_{50} / D$ of the form $B / D=a\left(d_{50} / D\right)^{b}$ was also examined for 
steady currents across all $D$, but it was not found to be significant at $90 \%$ confidence ( $p$-value $>0.1)$. Also, its use tended to degrade the overall predictive power of the individual relationships for $B / D$ within the larger and smaller cylinder populations respectively.

There are not sufficient data available to resolve detailed relationships between $B / D$ and $\theta$ under steady currents for shapes other than cylinders. The dashed line in Fig. 4 associated with spheres (all the spheres have $D \geq 3 \mathrm{~cm}$ ) is also a relationship of the form $B / D=f_{\theta}=a \theta^{b}$, where $b$ was set equal to the value of $b$ found for larger cylinders, but with $a$ reduced by a best-fit factor of 0.84 . Based on available observations, one may reasonably infer that spheres tend to bury less under mean currents than cylinders likely because their more rounded shape sheds eddies more weakly (c.f., Truelsen et al. 2005). However, more observations are needed before the bestfit exponential relation with $\theta$ can be confidently resolved for spheres.

In contrast to spheres, available data on tapered (i.e., bullet-shaped) cylinders suggest that they bury deeper than non-tapered cylinders of the same diameter. This may be associated with their tendency to rotate their blunt end toward the flow at an angle relatively close to $45^{\circ}$, enhancing the intensity of vortex shedding (Rennie et al., 2016). This is consistent with the finding of Sumer and Fredsøe (2002) that square pilings oriented at $45^{\circ}$ toward flow scour more intensely than round pilings or than square pilings oriented at $90^{\circ}$.

After normalizing by the relationships between $\theta$ and $B / D$ displayed in Fig. 4, parameterizations of the form $f_{\rho_{0}}=a\left(\rho_{\mathrm{o}} / \rho\right)^{b}$, where $\rho_{\mathrm{o}}$ is object density, were tested against $(B / D) f_{\theta}^{-1}$, which represents the remaining unexplained variance in $B / D$. A statistically significant relationship was found between object density and residual variance for larger cylinders ( $p$ value $<0.05$ ), but not for small cylinders, tapered cylinders or spheres. For all available cylinders with $D>2.6 \mathrm{~cm}$, significantly deeper burial was found under steady flow as $\rho_{\mathrm{o}} / \rho$ increased (Fig. 5). This trend is consistent with the findings of CatañoLopera and García (2006) for self-burying cylinders under waves and supports the conclusion that greater density of objects can favor deeper self-burial, even in the absence of bed fluidization.

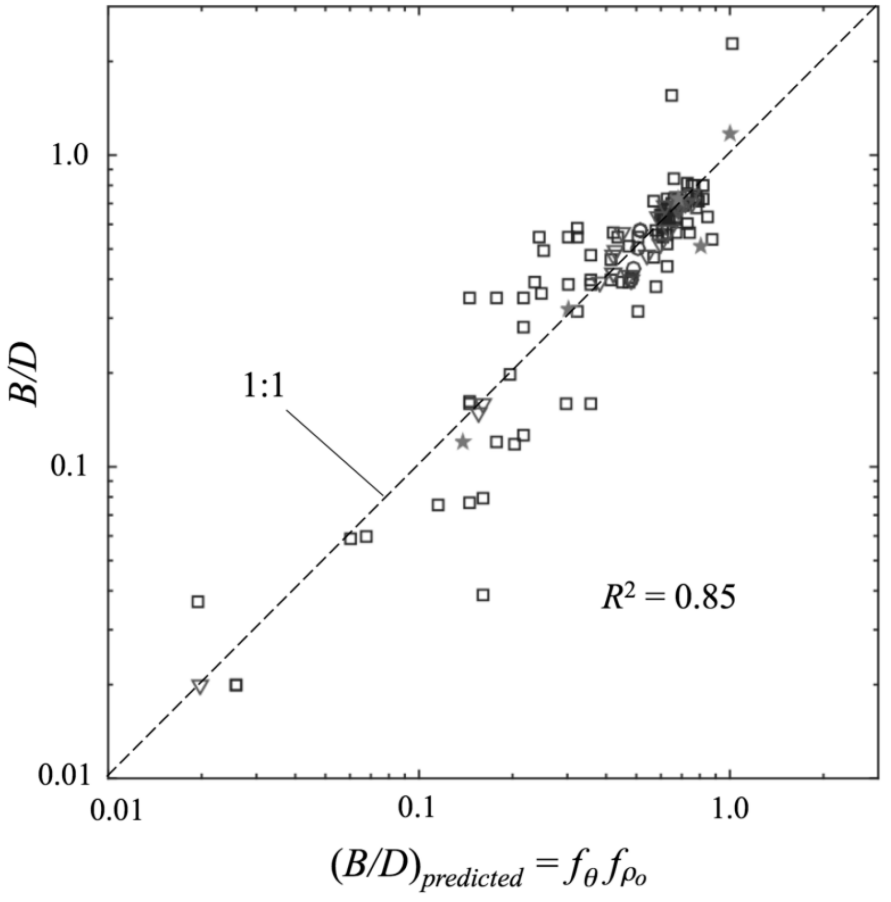

Figure 6. All available observations of $B / D$ for currents in the absence of waves, plotted as a function the final parameterized model for B/D under steady flow, (B/D)predicted $=\mathrm{f}$

Symbols are as in Fig. 4. The formulations and coefficients for $\mathrm{f}$

for $\star$, the coefficients for $\nabla$ and $\square$ were used for and greater than 0.04 , respectively. (Cases with $\mathrm{Uw}>0$, e.g., the field cases in Tables 1 and 2, are not included in Figs. 4, 5 or 6.)

After normalizing by the relationships between $\theta$ and $B / D$, parameterizations of the form $f_{L / D}=a(L / D)^{b}$ were also tested against $(B / D) f_{\theta}^{-1}$, but no significant relationships were found.

Combining the above results, the final parameterized model for predicted $B / D$ for self-burying objects subject to currents in the absence of waves is

$(B / D)_{\text {predicted }}=f_{\theta} f_{\rho_{\mathrm{o}}}$

with the formulations and coefficients for $f_{\theta}$ and $f_{\rho_{\mathrm{o}}}$ provided in Fig. 4 and Fig. 5. To calculate $f_{\theta}$ for tapered cylinders, the coefficients for large and small cylinders were used for $\theta$ less than and greater than 0.04 , respectively. For tapered cylinders, spheres and small cylinders, $f_{\rho_{0}}=1$. Fig. 6 compares Eq. (8) to all 126 available observations of self-burial of objects in sandy beds under steady currents in the absence of waves. For these cases, Eq. (8) explains $85 \%$ of the observed variance in $B / D$.

\subsection{Self-burial by scour under waves and under waves plus currents}

In contrast to steady currents, $K C$ alone is better correlated to $B / D$ in the presence of waves $\left(R^{2}=0.2\right)$ than is $\theta$ alone $\left(R^{2}=0.07\right)$, at least when all 635 available observations of object self-burial including waves from Fig. 2 and Fig. 3 are utilized. Thus the first parameter we consider in our step-wise multiple regression for $B / D$ under wave-dominated conditions is $K C$. 
Among the various classes of objects, simultaneously strong and very distinct relationships between $K C$ and $B / D$ were seen (i) for conical frustums under waves only (pluses in Fig. 7) and (ii) for cylinders under waves only (circles in Fig. 7, specifically for $D \geq 3 \mathrm{~cm}$ and $\alpha>60^{\circ}$ ). Here we define $f_{K C}=a(K C)^{b}$ to be the form of the power law function that represents the contribution of $K C$ to our final parameterized model for $B / D$ for all objects. The best-fit values for $a$ and $b$ for conical frustums under waves were also applied to conical frustums under waves plus currents. The best-fit values for $a$ and $b$ for cylinders under waves were applied to all the other cases in Fig. 7. (The best-fit lines in Fig. 7 were constrained almost exclusive by live-bed data, since $97 \%$ of the 0 and + points in Fig. 7 are cases for which $\theta>0.05$.)

The results found here for $B / D$ as a function of $K C$ are consistent with those reported by previous authors. Cataño-Lopera et al. (2011), the original source of the conical frustum data, reported a similar value for $b$, namely $B / D \sim K C^{4 / 5}$ (here we found $B / D$ $\sim K C^{0.79}$ ). However, they did not present a corresponding value for $a$. The best-fit power law relationship found here for the self-burial of cylinders, $B / D=0.10 K C^{0.51}$, is nearly identical to that reported by Sumer and Fredsøe (1990) for the depth of scour $(S)$ by waves under vertically fixed pipelines, $S / D=0.10 K C^{0.50}$

After normalizing by the relationship between $K C$ and $B / D$ that is displayed in Fig. 7, an equation of the form $f_{U c||}=\exp \left[-c\left(U_{c||} / U_{m}\right)\right]$ was tested against the remaining unexplained variance in burial, $(B / D) f_{K C}{ }^{-1}$. In the above exponential relation, $U_{c \mid l}$ is the component of the mean current that is parallel to wave orbital velocity. In lab flumes we let $U_{c \|}=U_{c}$, whereas for field data during storms on the inner shelf we assume $U_{c||} / U_{m} \approx 0$. (Note that in the field data, the effect of $U_{c}$ on scour is still included through its enhancement of $U_{m}$ in Eq. (7) and via the replacement of $U_{w}$ by $U_{m}$ in Eqs. (5) and (6).) The reason an exponential relation is used rather than a power law is that $f_{U c||}=\exp \left[-c\left(U_{c||} / U_{m}\right)\right]=1$ for $U_{c \| \mid} / U_{m}=0$. This allows a single value of $c$ to be used for both cases with waves alone and also cases with waves plus currents. Consistent with previous findings (Cataño-Lopera and García, 2006, CatañoLopera et al., 2011), $B / D$ was found to decrease as $U_{c||} / U_{m}$ increased (Fig. 8a). Fig. 8a pools cases for $U_{c||} / U_{m}>0$ for both cylinders and conical frustums in order to derive a single value of $c=-1.1$ valid for all available observations.

Next, after normalizing by $f_{U c \|}$, a relationship of the form $\left.f_{\alpha}=\exp \left[-c_{1}\left(\cos \alpha-c_{2}\right) U_{c||} / U_{m}\right)\right]$ was tested against $(B / D) f_{K C^{-1}} f_{U c \|} \|^{-1}$ (Fig. 8b), where $\alpha$ is the angle between wave orbital velocity and a cylinder's long axis. Consistent with the findings of CatañoLopera (2005), the original source of the data, $B / D$ was found to decrease as $\alpha$ decreases toward zero.

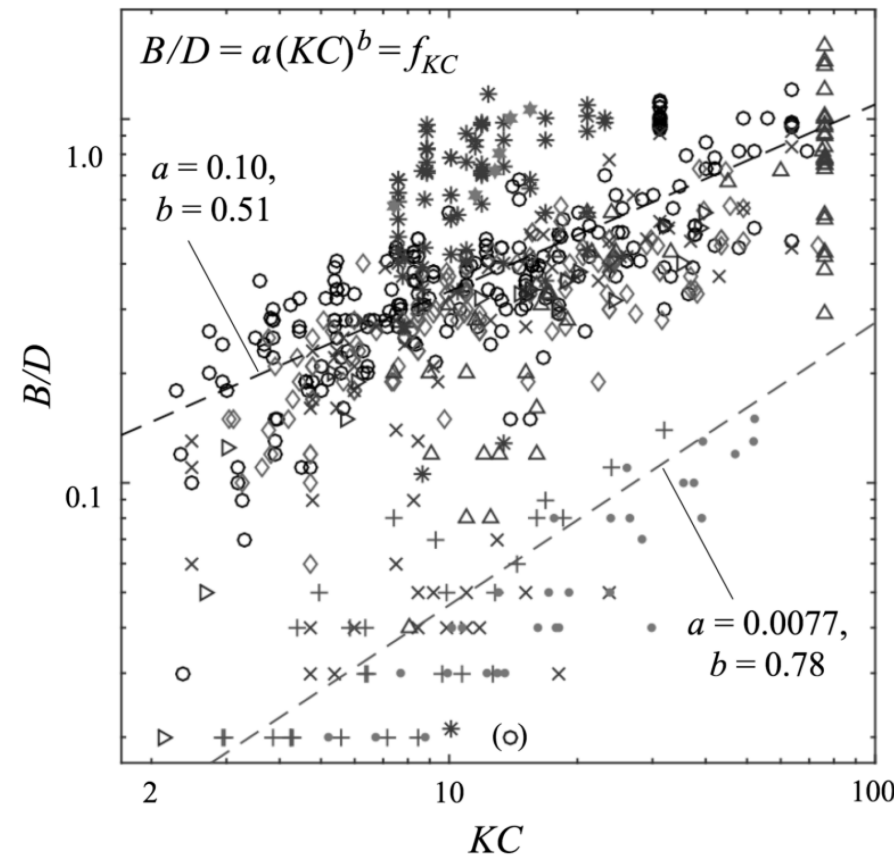

Figure 7. All observations of $B / D$ that include waves, plotted as a function of $K C$. Symbols are as in Fig. 2 except that here $\mathrm{O}=$ cylinders with waves only and $\triangleright=$ spheres with waves only. Best-fit relationships are shown above for $O$ and for + (conical frustums with waves only). The coefficients $a$ and $b$ displayed above are utilized in $f_{K C}$ as part of the relations applied in Fig. 8 through Fig. 11. (0) = assumed outlier not included in analysis.
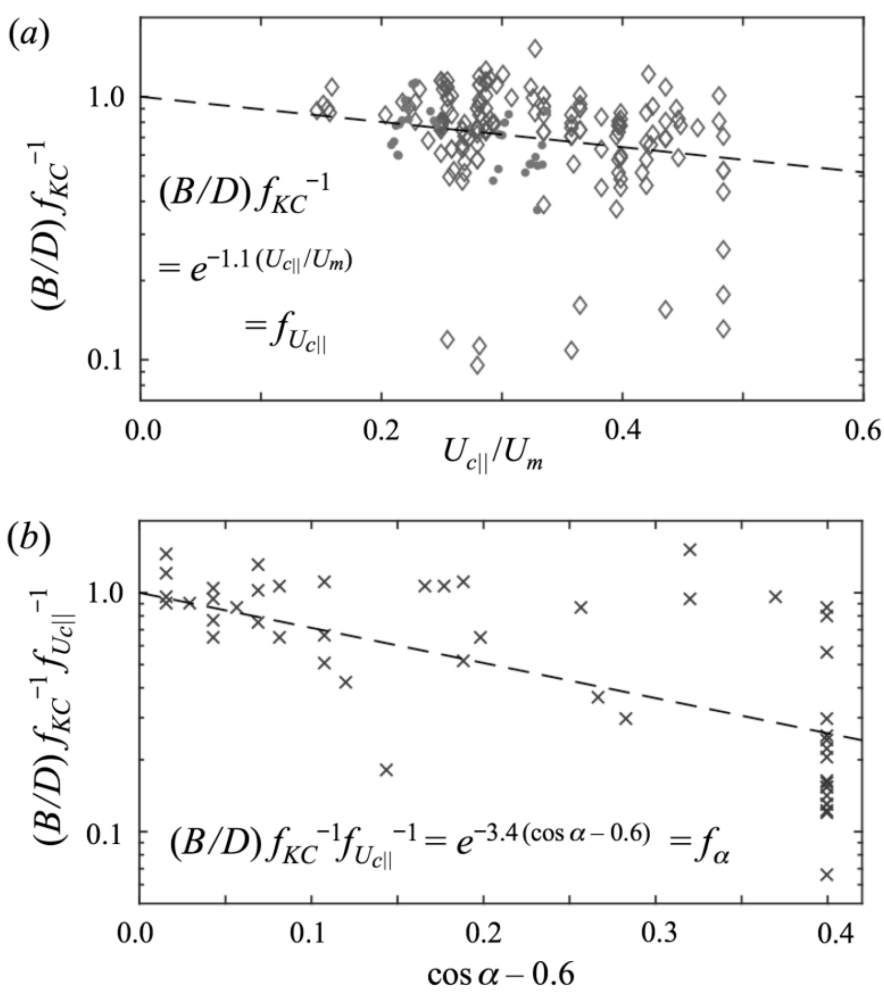

Figure 8. (a) $B / D$ normalized by the power-law relations from Fig. 7 and plotted as a function of $U_{c \mid} / U_{m}$ for all available data for which the mean current is parallel to the wave orbital velocity. Cylinders $=\diamond$; conical frustums $=\bullet$. (b) $B / D$ additionally normalized by the exponential relation from Fig. 8a and plotted as a function of $\cos \alpha$, for all available data with $\cos \alpha>0.6$, where $\alpha$ is final the angle between a cylinder's long axis and wave orbital velocity. The exponential relations associated with the dashed lines (fit to all data in each plot) are utilized in $f_{U c \mid}$ and $f_{\alpha}$ as part of the relations applied in Fig. 9 through Fig. 11. However, the resulting analyses of Cataño-Lopera (2005) and Cataño-Lopera and García (2007) re- 
garding the effects of $\alpha$ were graphical and did not provide a quantitative formulation its effects. The best-fit values of $c_{1}$ and $c_{2}$ found here, 3.4 and 0.6, provide an explicit method for accounting for $\alpha$.

Once the effects of $K C, U_{c||} / U_{m}$ and $\alpha$ had been removed from $B / D$, a strong remaining relationship between scour-induced burial and the Shield's parameter of the form $f_{\theta W}=a \theta^{b}$ was evident for observations of cylinders that involved waves (Fig. 9), including small cylinders observed in the lab $(D<2.6$ $\mathrm{cm})$ and relatively large cylinders observed in the field $(D \approx 50 \mathrm{~cm})$. The best-fit values for $a$ and for $b$ for cylinders, displayed in Fig. 9, were well constrained by hundreds of observations of normalized $B / D$. The dozens of observations of normalized $B / D$ for conical frustums were sufficient to confirm that no significant relationship exists between $\theta$ and $B / D$ $(p=0.86)$, and for conical frustums we set $f_{\theta W}=1$.

Trends for the exponent $b$ were found to be similar to that for cylinders for the cases of tapered cylinders and spheres, but with $a$ larger for tapered cylinders and smaller for spheres, respectively. A tendency for tapered cylinders to bury more and spheres less was likewise noted for steady currents (see Section 3.1). Here the well-constrained value of $b$ found for cylinders was also assigned to tapered cylinders and spheres, and $a$ was then chosen to maximize the overall fit.

Normalized $B / D$ as a function of $\theta$ in Fig. 9 suggests a transition occurs (i) from clear-water scour to classic live-bed scour under waves at $\theta \approx 0.05$ and (ii) from classic live-bed scour to fluidization of the upper bed via sheet flow at $\theta \approx 0.6$ (c.f., Dibajnia and Watanabe, 1992). These transition points are supported by the fact that the majority of values for normalized $B / D$ for cylinders fall well below the trend line in Fig. 9 for $\theta<0.05$ and fall well above the trend line for $B / D>0.6$. Thus the best-fit values of $a$ and $b$ displayed on Fig. 9 were calculated based only on observations for $0.05<\theta<0.6$.

The sudden transition to relatively complete burial for the field data, indicated by $*$ symbols at high $\theta$ in Fig. 9, provides evidence to support the use of $U_{w 10}$ to estimate $U_{\underline{w}}$ under random waves as suggested by Myhraug and Ong (2009). If a less energetic value of $U_{w}$ were used for the field data in Fig. 9 , such as $U_{w}=2^{1 / 2} \sigma_{\mathrm{U}}$ instead of $U_{w}=2 \sigma_{\mathrm{U}}$, then the transition to an influence of sheet flow/fluidization on burial for the most energetic field data would not be nearly as clear.

Parameterizations of the form $f_{\rho_{\mathrm{OW}}}=a\left(\rho_{\mathrm{o}} / \rho\right)^{b}$, where $\rho_{\mathrm{o}}$ is object density, were also tested against the remaining unexplained variance in $B / D$ under waves (Fig. 10). A statistically significant relationship was found for non-fluidized live-bed data from Fig. 9 within the range $1.7<\rho_{\mathrm{o}} / \rho<3.3$, but not outside this range of $\rho_{\mathrm{o}} / \rho$. Because $f_{\rho_{\mathrm{ow}}}=a\left(\rho_{\mathrm{o}} / \rho\right) b$ performed poorly outside of $1.7<\rho_{\mathrm{o}} / \rho<3.3, f_{\rho_{\mathrm{ow}}}$ was not utilized as part of the final parameterized model.

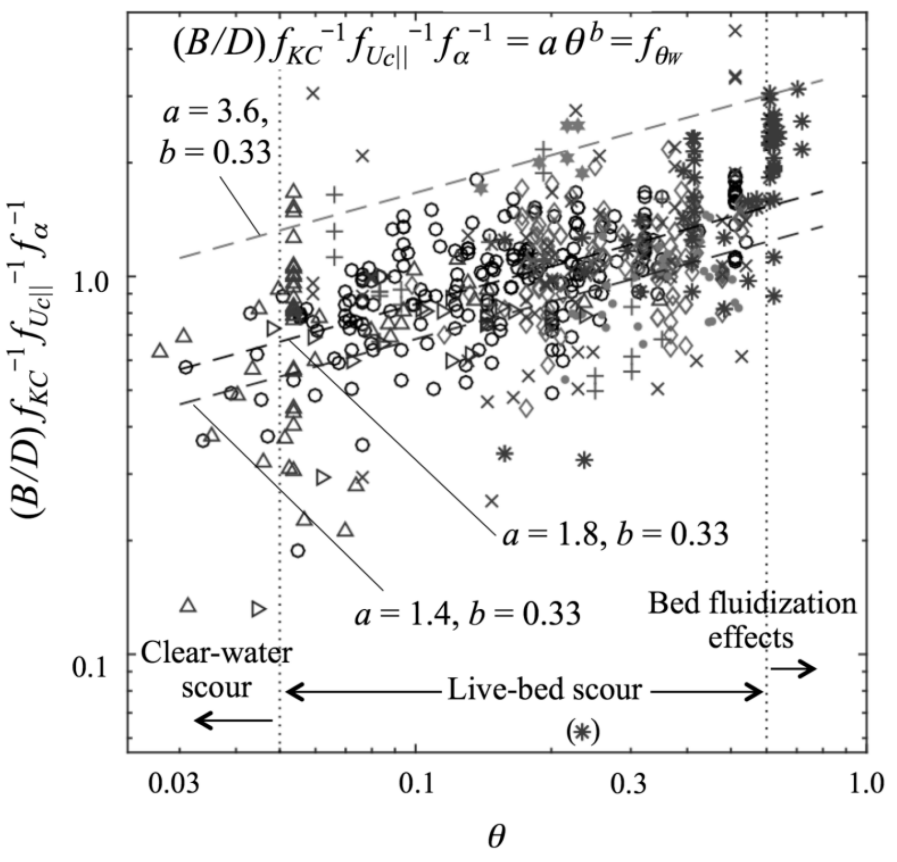

Figure 9 . $B / D$ normalized by the functional relationships from Fig. 7 and Fig. 8, and plotted as a function of $\theta$ for all cases that include waves. Symbols are as in Fig. 7. The coefficients $a$ and $b$ displayed above in association with the dashed lines are utilized in $f_{\theta W}$ as part of the relations applied in Fig. 10 and Fig. 11. From top to bottom, the dashed lines apply to tapered cylinders, cylinders, and spheres, respectively; $f_{\theta_{W}}=1$ for conical frustums. (*) $=$ assumed outlier not included in analysis.

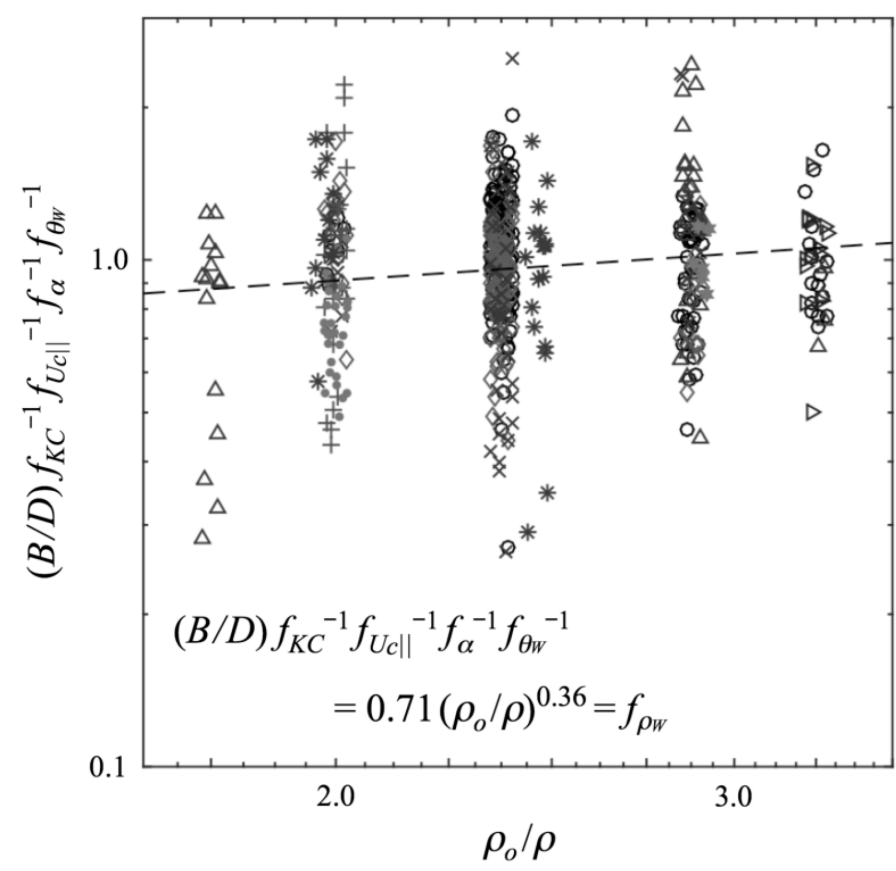

Figure $10 . B / D$ normalized by the functional relationships from Fig. 7 through Fig. 9, for all non-fluidized live-bed data from Fig. 9 available within the range $1.7<\rho_{\mathrm{O}} / \rho<3.3$. Symbols are as in Fig. 7 with minor random noise added to $\rho_{\mathrm{O}} / \rho$ to prevent complete visual overlap of symbols. Because it performed poorly outside of $1.7<\rho_{\mathrm{O}} / \rho<3.3$, the power law relation displayed above was not utilized as part of the final parameterized model.

Other parameters tested for importance to $B / D$ under waves included $L / D$ and $d_{50} / D$. However, neither of these ratios was found to have statistically 
significant effects on normalized $B / D$, either within specific classes of objects or across multiple classes of objects.

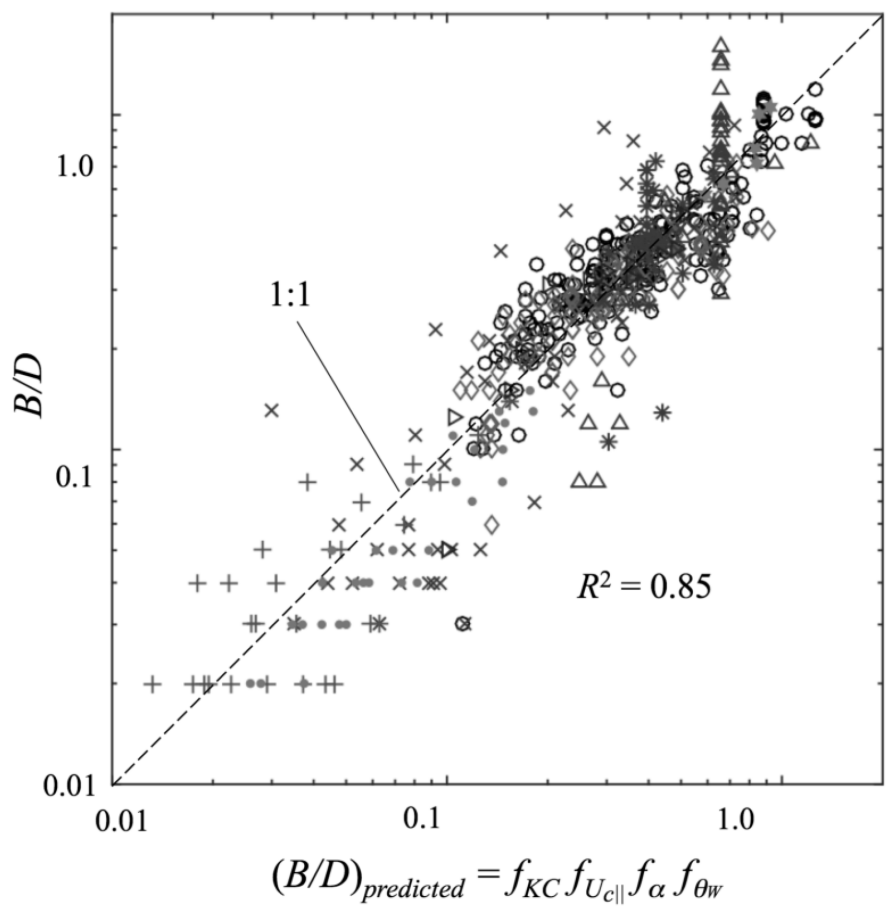

Figure 11. All available, non-fluidized, live-bed observations of $B / D$ under waves (including cases with waves plus currents), plotted as a function of the final parameterized model for $B / D$ under waves, $(B / D)$ predicted $=f_{K C} f_{U c||} f_{\alpha} f_{\theta_{W}}$. Symbols are as in Fig. 7. The formulations and coefficients for $f_{K C}, f_{U c \|}, f_{\alpha}$ and $f_{\theta W}$ are provided in Fig. 7, Fig. 8 and Fig. 9. (Cases with $U_{w}=0$ in Table 3 are not included in Figs. 7 to 11.)

Combining the above results, the final parameterized model for predicted $B / D$ for self-burying objects subject either to waves alone or to waves in combination with mean currents is

$(B / D)_{\text {predicted }}=f_{K C} f_{U c||} f_{\alpha} f_{\theta_{W}}$

with the formulations and coefficients for $f_{K C}, f_{U c \|}$, $f_{\alpha}$ and $f_{\theta_{W}}$ provided in Fig. 7, Fig. 8 and Fig. 9. For $f_{K C}$, the $a$ and $b$ values for lower dashed line in Fig. 7 were applied to conical frustums, while the values for the upper dashed line were applied to all other cases. The relationships in Fig. 8 apply to all observations under waves. In Fig. 9, the lines from top to bottom apply to tapered cylinders, cylinders and spheres, while $f_{\theta W}=1$ for conical frustums. Fig. 11 compares Eq. (9) to all 578 available observations of self-burial of objects in sand under non-fluidized, live-bed conditions under waves. For these cases, Eq. (9) explains $85 \%$ of the observed variance in $B / D$.

\section{CONCLUSIONS}

A compilation and analysis of 761 observations of equilibrium self-burial depth associated with scour on sandy beds is presented. Observed object burial- to-diameter ratios $(B / D)$ vary by a factor of $100, D$ by a factor of 50 , length-to-diameter ratios $(L / D)$ by a factor of 30 , object densities $\left(\rho_{0}\right)$ by a factor of 9 , and median sand size $\left(d_{50}\right)$ by a factor of 5 . Object shapes include cylinders, tapered cylinders, spheres and conical frustums. Nonetheless, simple parameterized models for $B / D$ are identified via an informal, step-wise least-squares regression approach that account for $85 \%$ of observed variance.

The main factor which increases scour-induced $B / D$ under steady currents $\left(U_{c}\right)$ in the absence of waves is found to be an increasing Shields parameter, $\theta=\tau_{b} /\left[\left(\rho_{\mathrm{s}}-\rho\right) g d_{50}\right]$, with distinctly different power law relations applicable to $B / D$ as a function of $\theta$ for clear-water and live-bed scour. Greater $B / D$ is observed as a function of $\theta$ for small cylinders $(D<3 \mathrm{~cm})$ and for tapered cylinders, while smaller $B / D$ is observed for spheres. After accounting for the effects of $\theta$, normalized $B / D$ for larger cylinders is observed in increase with greater $\rho_{\mathrm{o}}$.

The main factor which increases scour-induced $B / D$ under wave-dominated conditions is an increasing Keulegan-Carpenter number, $K C=U_{m} T / D$, with distinct power-law relations for conical frustums versus other object shapes, such that conical frustums bury less. After accounting for effects of $K C$, normalized $B / D$ is shown to decrease as the strength of the component of $U_{c}$ parallel to wave orbital velocity increases and as the angle between orbital velocity amplitude, $U_{w}$, and a cylinder's long axis decreases. Normalized $B / D$ under waves is also shown to generally increase as a function of $\theta$, with larger $B / D$ at a given $\theta$ for tapered cylinders relative to cylinders, and smaller $B / D$ at a given $\theta$ for spheres relative to cylinders.

Finally, observations of $B / D$ in the field suggest that the highest $10 \%$ of $U_{w}$ may better represent scour in random waves, and they highlight the likely importance of burial by bed fluidization associated with sheet flow at high $\theta$.

\section{ACKNOWLEDGEMENTS}

This work was supported by funding from Contracts MR-2224 and MR-2227 awarded by the US Department of Defense Strategic Environmental Research and Development Program. We are grateful to anonymous reviewers for their valuable comments which significantly improved the paper. This article is contribution No. 3550 of the Virginia Institute of Marine Science, College of William and Mary. 


\section{REFERENCES}

Bradley, J., Griffin, S., Thiele, M., Richardson, M.D. \& Thorne, P.D. 2007. An acoustic-instrumented mine for studying subsequent burial. IEEE Journal of Oceanic Engineering 32(1): 91-102.

Bower, G.R., Richardson, M.D., Briggs, K.B., Elmore, P.A., Braithwaite, E.F., Bradley, J., Griffin, S., Wever, T.F. \& Lühder, R. 2007. Measured and predicted burial of cylinders during the Indian Rocks Beach experiment. IEEE Journal of Oceanic Engineering 32(1): 91-102.

Carstens, M.R. \& Martin, C.S. 1963. Settlement of cylindrical mines into the seabed under gravity waves. Final Report, US Navy Mine Defense Laboratory, Project No. A-628.

Cataño-Lopera, Y.A. 2005. Burial of short cylinders induced by local sour and bedform migration under waves plus currents. PhD Thesis, College of Engineering, University of Illinois at Urbana-Champaign.

Cataño-Lopera, Y.A., Demir, S.T. \& García, M.H. 2007. Selfburial of short cylinders under oscillatory flows and combined waves plus currents. IEEE Journal of Oceanic Engineering 32(1): 191-203.

Cataño-Lopera, Y.A. \& García, M.H. 2006. Burial of short cylinders induced by scour under combined waves and currents. ASCE Journal of Waterway Port Coastal and Ocean Engineering 132(6): 439-449.

Cataño-Lopera, Y.A. \& García, M.H. 2007. Geometry of scour hole around, and the influence of the angle of attack on the burial of finite cylinders under combined flows. Ocean Engineering 34(5): 856-869.

Cataño-Lopera, Y.A., Landry, B.J. \& García, M.H. 2011. Scour and burial mechanics of conical frustums on a sandy bed under combined flow conditions. Ocean Engineering 38(10): 1256-1268.

Dean, R.G. \& Dalrymple, R.A. 1991. Water wave mechanics for engineers and scientists. Singapore: World Scientific.

Demir, S.T. \& García, M.H. 2007. Experimental studies on burial of finite-length cylinders under oscillatory flow. ASCE Journal of Waterway Port Coastal and Ocean Engineering 133(2): 117-124.

Dibajnia, M. \& Watanabe, A. 1992. Sheet flow under nonlinear waves and currents. Coastal Engineering Proceedings 23: 2015-2028.

Friedrichs, C.T. 2007. Reformulation of mine scour equations using observations from MBP field sites. Final Report. US Office of Naval Research Coastal Geosciences Program, Grant N00014-05-1-0112.

Friedrichs, C.T., Rennie, S.E \& Brandt, A. 2016. Simple parameterized models for predicting mobility, burial and reexposure of underwater munitions. Final Report. US Strategic Environmental Research and Development Program, Project MR-2224.

García, M.H., Sediment transport and morphodynamics. In: M.H. García (ed.), Sedimentation engineering: processes, measurements, modeling and practice: 21-163. Reston, Virginia: American Society of Civil Engineers.

Jenkins, S.A., Inman, D.L., Richardson, M.D., Wever, T.F. \& Wasyl, J. 2007. Scour and burial mechanics of objects in the nearshore. IEEE Journal of Oceanic Engineering 32(1): 78-90.

Mayer, L.A., Raymond, R., Glang, G., Richardson, M.D., Traykovski, P. \& Trembanis, A.C., 2007. High-resolution mapping of mines and ripples at the Martha's Vineyard Coastal Observatory. IEEE Journal of Oceanic Engineering 32(1): 133-149.

Myrhaug, D. \& Slaattelid, O.H. 1990. A rational approach to wave-current friction coefficients for rough, smooth, and transitional turbulent flow. Coastal Engineering 14(3): 265-293.
Myrhaug, D. \& Ong, M.C. 2009. Burial and scour of short cylinders under combined random waves and currents including effects of second order wave asymmetry. Coastal Engineering 56(1): 73-81.

McNinch, J.E., Wells, J.T. \& Trembanis, A.C. 2006. Predicting the fate of artefacts in energetic, shallow marine environments: an approach to site management. International Journal of Nautical Archaeology 35(2): 290-309.

Pang, C. \& Liu, L. 2014. Variability of sand mobility surrounding cylinder object freely resting on the seabed under the action of typhoon. International Journal of Geosciences 5(7): 690-699.

Rennie, S.E., Brandt, A. \& Friedrichs, C.T. 2016. Initiation of motion and scour burial of objects underwater. Ocean Engineering in review.

SERDP 2009. Munitions in the underwater environment: state of the science and knowledge gaps. Strategic Environmental Research and Development Program White Paper. US Department of Defense.

Stansby, P.K. \& Starr, P. 1992. On a horizontal cylinder resting on a sand bed under waves and currents. International Journal of Offshore and Polar Engineering 2(4): 262-266.

Starr, P. 1989. Mobile bed interaction with a cylinder under currents and waves. PhD Thesis, University of Manchester.

Sumer, B.M. 2014. Liquefaction around marine structures. Singapore: World Scientific.

Sumer, B.M. \& Fredsøe, J. 1990. Scour below pipelines in waves. ASCE Journal of Waterway Port Coastal and Ocean Engineering 116(3): 307-323.

Sumer, B.M. \& Fredsøe, J. 1994. Self-burial of pipelines at span shoulders. International Journal of Offshore and Polar Engineering 4(1): 189-194.

Sumer, B.M. \& Fredsøe, J. 2002. The mechanics of scour in the marine environment. Singapore: World Scientific.

Sumer, B.M., Truelsen, C., Sichmann, T. \& Fredsøe, J. 2001. Onset of scour below pipelines and self-burial. Coastal Engineering 42(4): 313-335.

Traykovski, P., Richardson, M.D., Mayer, L.A. \& Irish, J.D. 2007. Mine burial experiments at the Martha's Vineyard Coastal Observatory. IEEE Journal of Oceanic Engineering 32(1): 150-166.

Trembanis, A.C., Friedrichs, C.T., Richardson, M.D., Traykoviski, P., Howd, P.A., Elmore, P.A. \& Wever, T.F. 2007. Predicting seabed burial of cylinders by wave-induced scour: application to the sandy inner shelf off Florida and Massachusetts. IEEE Journal of Oceanic Engineering 32(1): 167-183.

Truelsen, C., Sumer, B.M. \& Fredsøe, J. 2005. Scour around spherical bodies and self-burial. ASCE Journal of Waterway Port Coastal and Ocean Engineering 131(1): 1-13.

Voropayev, S.I., McEachern, G.B., Boyer, D.L. \& Fernando, H.J.S. 1999. Dynamics of sand ripples and burial/scouring of cobbles in oscillatory flow. Applied Ocean Research 21(5): 249-261.

Voropayev, S.I., Testik, F.Y., Fernando, H.J.S. \& Boyer, D.L. 2003. Burial and scour around short cylinder under progressive shoaling waves. Ocean Engineering 30: 1647-1667.

Whitehouse, R., 1998. Scour at marine structures. London: Thomas Telford.

Wolfson, M. L., 2005. Multibeam observations of mine scour and burial near Clearwater, Florida, including a test of the VIMS 2D mine burial model. MS Thesis, College of Marine Science, University of South Florida.

Wolfson, M.L., Naar, D.F., Howd, P.A., Locker, S.D., Donahue, B.D., Friedrichs, C.T., Trembanis, A.C., Richardson, M.D. \& Wever, T.F. 2007. Multibeam observations of mine burial near Clearwater, Florida, including comparisons to predictions of wave-induced burial. IEEE Journal of Oceanic Engineering 32(1): 103-118.

Yalin, M.S. 1992. River mechanics, New York: Pergamon. 